\title{
Molecular cloning and expression analysis of the STATI gene from olive flounder, Paralichthys olivaceus Eun-Mi Park ${ }^{1}$, Jung-Ha Kang${ }^{1}$, Jung Soo Seo ${ }^{2}$, GunDo Kim³, Jongkyeong Chung ${ }^{4}$ and Tae-Jin Choi*1,3
}

\begin{abstract}
Address: ${ }^{1}$ Biotechnology Research Institute, National Fisheries Research and Development Institute, 408-1, Sirang-Ri, Gijang-Eup, Gijang-Gun, Busan, 619-902, Republic of Korea, 2Pathology Division, National Fisheries Research and Development Institute, 408-1, Sirang-Ri, Gijang-Eup, Gijang-Gun, Busan, 619-902, Republic of Korea, ${ }^{3}$ Department of Microbiology, Pukyong National University, 599-1 Daeyeon-Dong, Nam-Gu, Busan, 608-737, Republic of Korea and ${ }^{4}$ Department of Biological Sciences, Korea Advanced Institute of Science and Technology, Taejon, 305-701, Republic of Korea

Email: Eun-Mi Park - empark@pknu.ac.kr; Jung-Ha Kang - jhkang@nfrdi.re.kr; Jung Soo Seo - jsseosoo@hanmail.net;

GunDo Kim - gundokim@pknu.ac.kr; Jongkyeong Chung - jchung@kaist.ac.kr; Tae-Jin Choi* - choitj@pknu.ac.kr

* Corresponding author

Published: 26 June 2008

BMC Immunology 2008, 9:3। doi:10.1|86/|47|-2|72-9-31

Received: 20 February 2008

Accepted: 26 June 2008

This article is available from: http://www.biomedcentral.com/I47I-2I72/9/3I

(c) 2008 Park et al; licensee BioMed Central Ltd.

This is an Open Access article distributed under the terms of the Creative Commons Attribution License (http://creativecommons.org/licenses/by/2.0), which permits unrestricted use, distribution, and reproduction in any medium, provided the original work is properly cited.
\end{abstract}

\begin{abstract}
Background: Signal transducer and activator of transcription I (STATI) is a critical component of interferon (IFN)-alpha/beta and IFN-gamma signaling. Although seven isoforms of STAT proteins have been reported from mammals, limited information is available for the STAT genes in fish. We isolated complementary DNA with high similarity to mammalian STATI from the olive flounder, Paralichthys olivaceus.
\end{abstract}

Results: A DNA fragment containing the conserved $\mathrm{SH} 2$ domain was amplified by RT-PCR using degenerate primers designed based on the highly conserved sequences in the $\mathrm{SH} 2$ domains of the zebrafish and mammalian STATI. The complete cDNA sequence was obtained by $5^{\prime}$ and 3 ' RACE. The flounder STATI transcript consisted of 2,909 bp that encoded a polypeptide of 749 amino acids. The overall similarity between flounder STATI and other STATs was very high, with the highest amino acid sequence identity to snakehead (89\%). Phylogenetic analyses reveal that flounder STATI is in the same monophyletic group with snakehead STATI. Quantitative real time RT-PCR and in situ hybridization revealed that STATI was expressed in almost all examined organs and tissues, with high expression in gill, spleen, kidney, and heart. The accumulation of STATI mRNA in different developmental stages, as determined by real time RT-PCR, increased with development.

Conclusion: Recent cloning of various cytokine genes and the STATI gene of olive flounder here suggest that fish also use the highly specialized JAK-STAT pathway for cytokine signaling. Identification of other STAT genes will elucidate in detail the signal transduction system in this fish.

\section{Background}

Cellular responses to internal and external signals are mediated by the expression of specific genes or sets of genes, which are regulated by specific transcriptional fac- tors [1]. Therefore, the entry of transcription factors into the nucleus is critical to their role in gene expression. Signals from cytokines and growth factors are transduced into the nucleus by the Janus kinase (JAK)-signal trans- 
ducers and activators of transcription (STAT) signaling pathway [2-6]. JAK-STAT signaling is also involved in the regulation of cell proliferation, differentiation, survival, motility, and apoptosis in different organs [7].

The binding of signal molecules to their receptors initiates activation of JAKs, which increases their tyrosine kinase activity $[4,8]$. The activated JAKs phosphorylate tyrosine residues on the receptor, which turns into a binding site for proteins that contain phosphotyrosine-binding Src homology 2 (SH2) domains such as STATs [9]. The STATs bound to the phosphorylated receptor are then tyrosinephosphorylated by JAKs. These phosphorylated STATs act as docking sites for other STATs, which results in dimerization. Activated STAT dimers accumulate in the nucleus, bind to consensus DNA-recognition motifs in the promoter regions of cytokine-inducible genes, and activate transcription of these genes $[4,10]$. STATs are also activated by non-receptor tyrosine kinases such as v-Src and receptor tyrosine kinases such as growth factor receptors $[11,12]$.

There are seven distinct STATs in mammals (STAT1, 2, 3, $4,5 \mathrm{a}, 5 \mathrm{~b}$, and 6 ) that participate in JAK-STAT signal transduction with different JAKs (JAK1, 2, 3, and Tyk2). STAT1, 2,4 , and 6 are expressed mainly in specific cell types and participate predominantly in host defense mechanisms; STAT1 is critical for interferon (IFN) function and innate immunity [13-15]. For example, STAT1 is selectively stimulated by IFN-gamma which has antiviral, immunoregulatory, and anti-tumor properties [14-16]. In mice lacking STAT1, all physiological functions associated with IFNs are absent, leading to a remarkable sensitivity to viral infections and other pathological agents $[14,15]$. This important physiological activity of STAT1 is expected to be conserved in fishes. Indeed, ectopic expression of the zebrafish STAT1 rescues IFN-induced signaling in a STAT1-deficient human cell line, indicating that the IFN/ STAT1-dependent signaling pathway in mammals might be functionally and structurally conserved in fishes [17]. In support of this, hirame rhabdovirus (HRV)-infected olive flounder have leukocytes with upregulated levels of mRNA for the components of the IFN/STAT1-dependent signaling pathway, such as interferon-inducible $56 \mathrm{~K}$ protein (IFI56), CEF-10, and STAT3 [18].

Recently, flounder interleukin-8, IFN-alpha, IFN-beta, and type- 1 cytokine receptors were cloned and characterized $[19,20]$, which suggest the presence of STAT genes in this fish. In addition, a number of cytokines and growth factors have been cloned, and their activities have been successfully detected in rainbow trout and carp [21]. However, limited information is available on STAT1 in edible fishes, despite recent efforts to understand IFNmediated anti-viral activity in fish. In this study, we present for the first time the cloning and expression analysis of a olive flounder STAT1.

\section{Results and Discussion Amplification of the SH2 Domain}

The STAT1 molecule can be divided into seven functional domains: an $\mathrm{N}$-domain responsible for dimer-dimer interactions, a coiled-coil domain responsible for proteinprotein interactions, a DNA-binding domain, a linker domain implicated in transcription, an $\mathrm{SH} 2$ domain responsible for receptor binding and dimerization, a tyrosine phosphorylation site, and a transcriptional activation domain [22]. Among these seven domains, the SH2 domain shows the highest amino acid sequence similarity between various species and between STAT families. For example, the STAT1 SH2 domains of human and zebrafish show $82 \%$ identity.

This structural conservation of the STAT SH2 domain in different species prompted us to clone STAT1 from P. olivaceus. First we constructed three degenerative PCR primers that represent three highly conserved peptide sequences within the $\mathrm{SH} 2$ domains of zebrafish and human STAT1, and conducted degenerative PCR reactions. The strategy for degenerative PCR used in the experiments is depicted in Fig. 1C. PCR product of 800 bp and $450 \mathrm{bp}$ were obtained from first round and second round PCR reaction, respectively. As a control, parallel PCR experiments were conducted with zebrafish cDNA, and we obtained a similar result, a 450 -bp PCR product, with the same primers used for flounder (data not shown). These results strongly suggest that the 800-bp PCR product encodes a partial sequence of flounder STAT1.

To confirm that the nested PCR product is flounder STAT1, we cloned and sequenced the PCR product. The cloned cDNA was 461 bp and contained sequences that perfectly matched with the primers.

\section{Complete Sequence of the Flounder STATI}

The complete cDNA of the flounder STAT1 gene was compiled by overlapping the sequences of the cloned cDNA and the 5'-RACE and 3'-RACE PCR products. The flounder STAT1 transcript consisted of 2,909 bp, which translated into a 749-amino acid (aa) open reading frame (ORF) that included an 103-bp 5'-untranslated region (5'-UTR) and a 556-bp 3'-UTR. The assembled full-length cDNA sequence was entered in GenBank under accession number EF491182. The flounder STAT1 protein is the same size as that of zebrafish (749 aa), similar to that of rainbow trout (754 aa), and larger than that of crucian carp (718 aa), which is missing 39 aa at the C-terminal end. The flounder STAT1 protein contains the conserved domains of STAT proteins; the N-terminal domain (1136), coiled-coiled domain (137-313), DNA binding 
A.

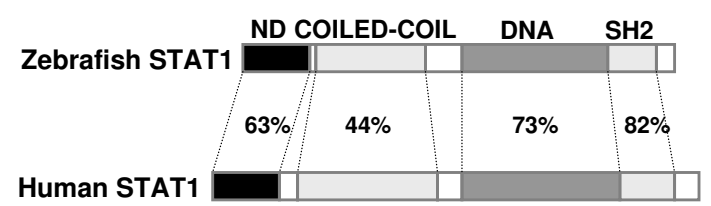

B.

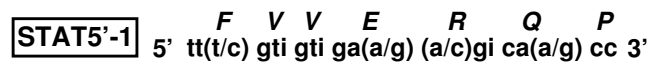
\begin{tabular}{|l|cccccc}
$S$ & $L$ & $P$ & $V$ & $V$ & $V$ & $I$ \\
5 & tci cti cci gti gti gti at & 3
\end{tabular}

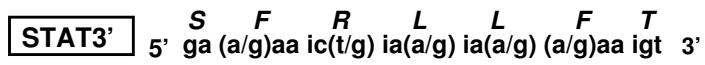

C.

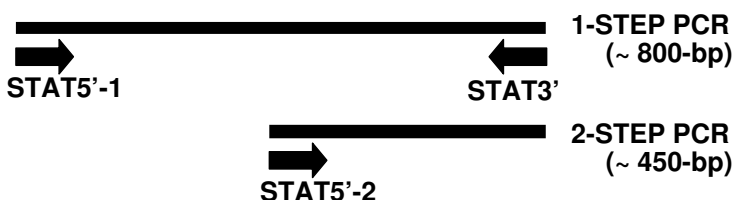

Figure I

Cloning of flounder STATI cDNA. (A) Comparison of the domain structure of human STATI to zebrafish STATI. $\mathrm{ND}, \mathrm{N}$-domain responsible for dimer-dimer interactions; COILED-COIL, coiled-coil domain responsible for proteinprotein interactions; DNA, DNA-binding domain; $\mathrm{SH} 2$, src homology 2 domain responsible for receptor binding and dimerization. (B) The degenerative PCR primers used in the experiments. (C) PCR strategies used to clone flounder STATI. The STAT5'-I and STAT3' primers were used for first-round PCR, and the STAT5'-2 and STAT3' primers were used for nested PCR.

domain (314-483), a linker (484-573), SH2 domain (574-679), and the transcriptional activation domain (680-749). The deduced flounder sequence contains a conserved tyrosine phosphorylation site $\left(\mathrm{Y}_{697}\right)$ in the Cterminal activation domain. In addition, it contains the $\mathrm{E}_{422} \mathrm{E}$ - and $-\mathrm{V}_{451} \mathrm{VV}$ - residues that are involved in DNA binding activity [23], $-\mathrm{P}_{719} \mathrm{MSP}$ for serine phosphorylation [24], and the arginine residue $\left(\mathrm{R}_{599}\right)$ that is required for SH2 phosphotyrosine binding [25].

The amino acid sequence of the putative flounder STAT1 was compared to known STATs from different species (Fig. 2). The overall similarity between the flounder STAT1 and other STATs was very high; snakehead STAT1 showed the highest identity (89\%) and similarity (93\%) at the amino acid level. Crucian carp STAT1 showed the lowest $61 \%$ identity and $77 \%$ similarity (Table 1 ). Figure 3 shows the phylogenetic tree based on amino acid sequence similarity. Flounder STAT1 belonged to the same monophyletic group as snakehead STAT1 (Fig. 3). Zebrafish STAT1 and human STAT1 were also included in the same monophyletic group. These results strongly indicate that the cloned DNA in this study indeed encodes the ortholog of flounder STAT1. We also note that the flounder STAT1 SH2 domain has been well conserved, and that it should play similar roles regulating STAT1 activity. As mentioned previously, zebrafish STAT1 can compensate for human STAT1 in inducing IFN-mediated signaling pathways in STAT1-deficient human cell lines [17]. Because zebrafish and flounder STAT1 have very high similarity (Table 1), we expect that flounder STAT1 also plays important roles in IFN-mediated immune activity in flounder.

\section{Northern Blot Analysis of Flounder STATI Genes}

We examined the mRNA expression of flounder STAT1 by Northern blot analyses. As a control, zebrafish total RNA was analyzed using zebrafish STAT3 cDNA as a probe. As shown in Fig. 4A, we detected bands of approximately 2.5 and $3 \mathrm{~kb}$. According to a previous report, the former corresponds to STAT3 and the latter to STAT1 in zebrafish [17]. Cross-reactivity of STAT3 with STAT1 mRNA is possible because the probe was derived from a 465-bp PCR fragment from the conserved $\mathrm{SH} 2$ domain, which has $64.7 \%$ nucleotide sequence identity between STAT1 and STAT3 [17]. Similarly, we examined STAT1 expression in flounder and observed a single $3-\mathrm{kb}$ message, which is almost the same size as the zebrafish STAT1 [17]. Considering the high sequence similarity in the $\mathrm{SH} 2$ domain of zebrafish STAT1 and STAT3, we expected see an mRNA band for STAT3 but did not detect another band (Fig. 4B). Although seven STAT genes have been identified in mammals [3], only STAT1, STAT3, and STAT5 have been identified in zebrafish $[17,26]$, STAT1 in rainbow trout and crucian carp [27], and STAT5 in pufferfish [28]. In zebrafish, only cDNA clones containing STAT3 were detected using a probe derived from STAT1. The presence of different forms of STAT genes in other fish but failure in the detection of STAT3 with the conserved SH2 domain probe in flounder suggests the possibility of finding more STAT genes in flounder with low nucleotide sequence similarity.

\section{Expression of Flounder STATI in Different Tissues and Developmental Stages}

Some STATs, including STAT3, are expressed in early stages of development, and null mutants for STAT3 in mice are embryonic lethal [29]. In contrast, STAT1 in vertebrates is dispensable for normal development [14]. Early expression of mouse STAT1 has been detected only in endothelial cells of decidual vasculature and decidual cells, which indicates maternal expression of this gene [30]. Similarly, zebrafish STAT1 gene expression was not detected by in situ hybridization before 6 days post-fertilization (dpf) [17]. As shown in Fig. 5A, flounder STAT1 expression could be detected in all developmental stages, 


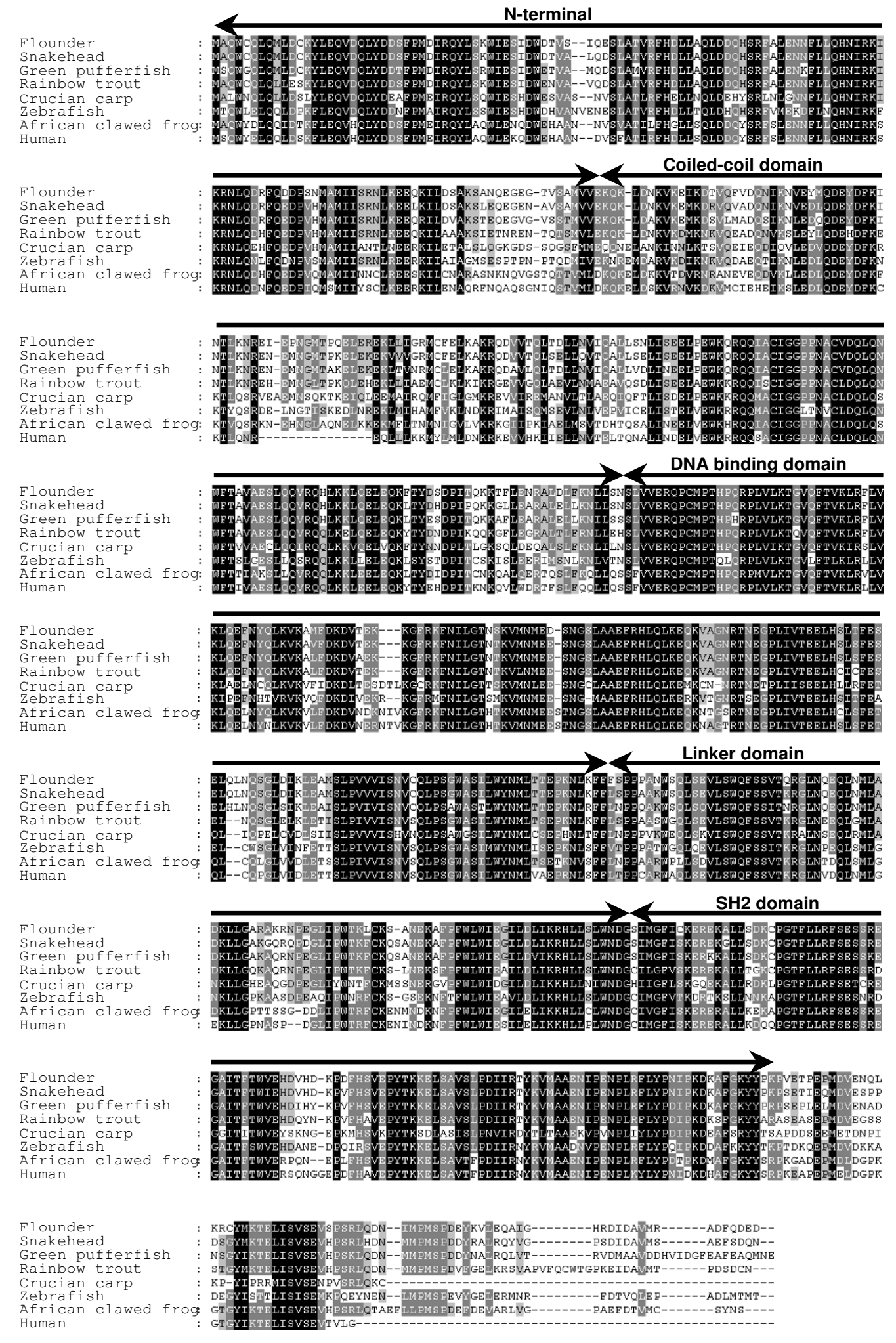

Figure 2

Amino acid sequence alignments of STATI proteins. Conserved amino acid residues are highlighted. 


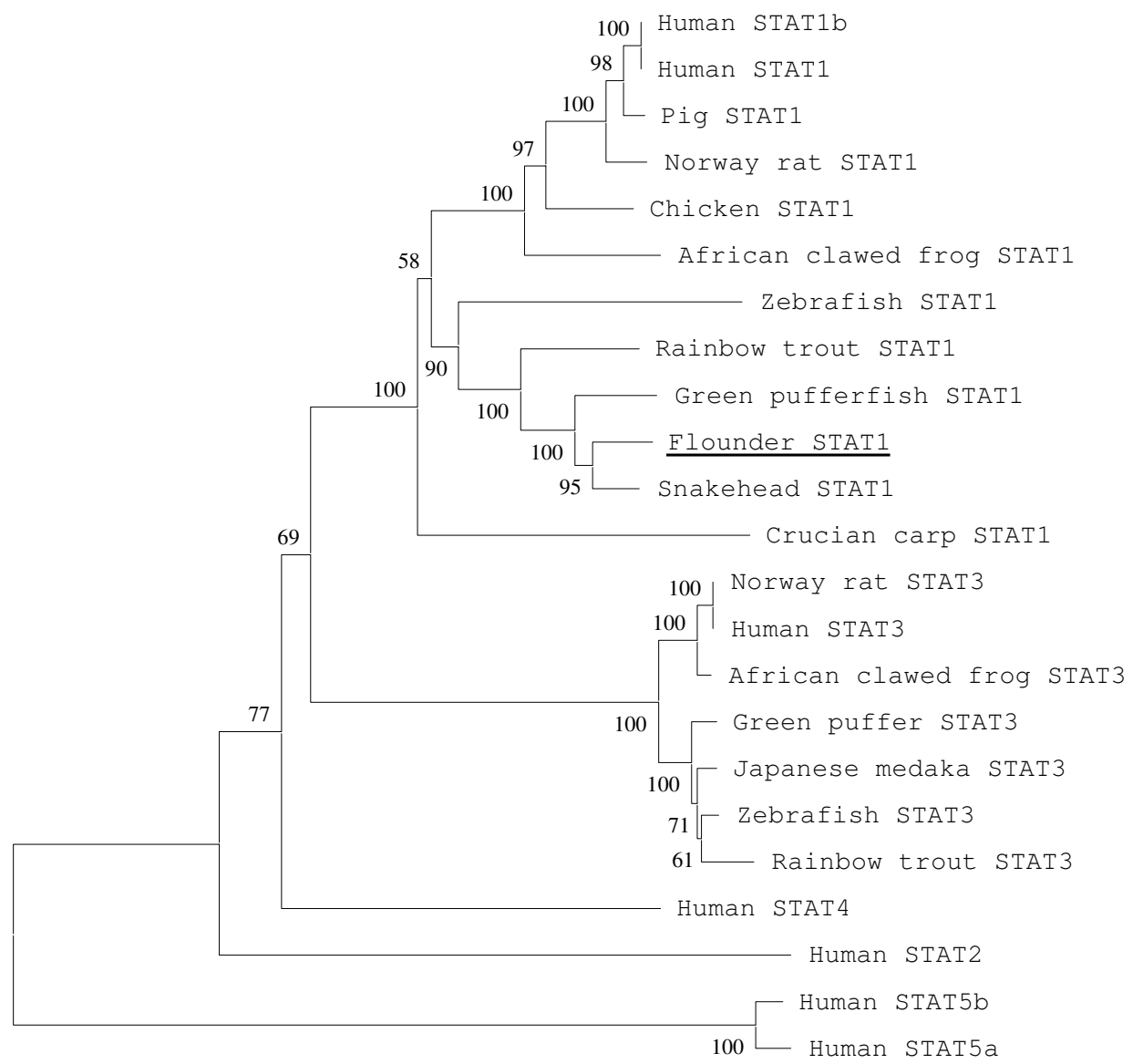

0.1

\section{Figure 3}

Phylogenetic tree of the STAT family transcription factors based on amino acid sequences. A phylogenetic tree of the aligned sequences was constructed using the neighbor-joining algorithm in MEGA (version 3.0). The confidence for each node was determined by bootstrap analysis (1000 repetitions).

Table I: Amino acid sequence similarities (top-right) and identities (bottom-left) of STATI proteins ${ }^{\mathrm{a}}$

\begin{tabular}{|c|c|c|c|c|c|c|c|c|}
\hline & Human & African Clawed frog & Zebrafish & Crucian carp & Rainbow trout & Green pufferfish & Snakehead & Flounder \\
\hline Human & & 88 & 77 & 76 & 82 & 79 & 80 & 80 \\
\hline African clawed frog & 79 & & 76 & 75 & 81 & 79 & 80 & 79 \\
\hline Zebrafish & 62 & 61 & & 72 & 79 & 78 & 78 & 78 \\
\hline Crucian carp & 60 & 60 & 56 & & 78 & 76 & 77 & 77 \\
\hline Rainbow trout & 69 & 68 & 66 & 62 & & 87 & 88 & 89 \\
\hline Green pufferfish & 68 & 65 & 63 & 60 & 78 & & 93 & 91 \\
\hline Snakehead & 68 & 66 & 65 & 61 & 79 & 87 & & 93 \\
\hline Flounder & 68 & 65 & 64 & 61 & 79 & 85 & 89 & \\
\hline
\end{tabular}

a Values are given as percentages.

including the fertilized egg. Also, expression of STAT1 increased in accordance with development. Increased mouse STAT1 expression has been observed from postnatal day 0 to adulthood in the cerebellum and cerebral cor- tex. In our experiment, total RNA was extracted from fertilized eggs and later developmental stages. Therefore, the site of STAT1 expression could not be determined and needs to be further characterized. 


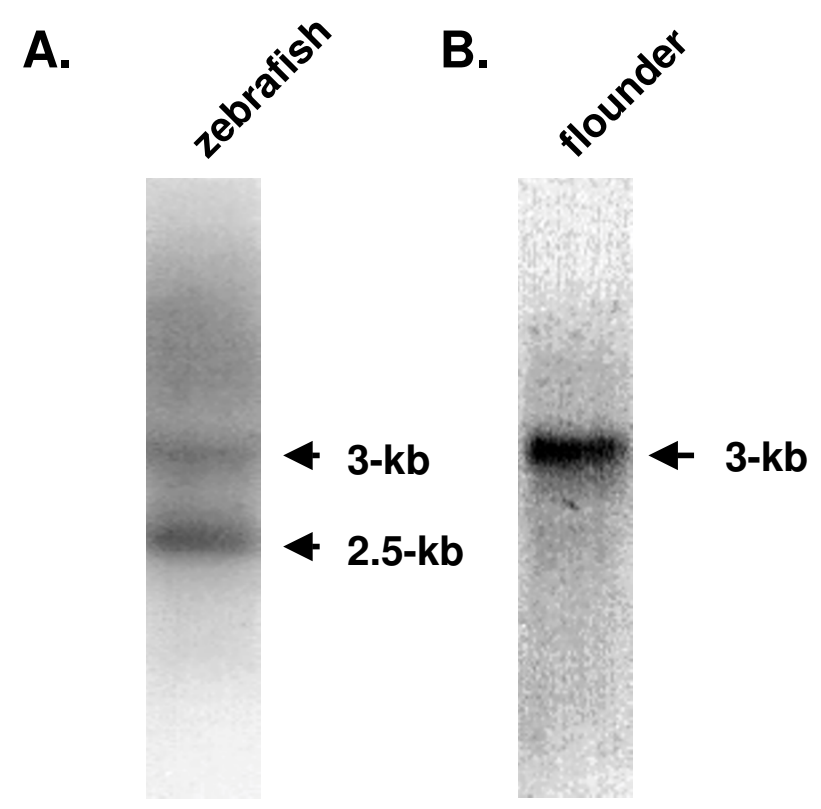

Figure 4

Northern blot analysis of flounder STATI. (A)

Zebrafish mRNA was used as a positive control that showed STATI (upper band) and STAT3 (lower band) mRNA. (B) Flounder mRNA detected with a flounder STATI SH2 domain-specific probe.

There are many reports of STAT1 expression in different tissues or cells of vertebrates, but studies of expression of fish STAT proteins in different tissues are limited. Sung et al. [28] observed the same expression of STAT5 in different tissues. We analyzed the expression of flounder STAT1 mRNA using quantitative real time RT-PCR and in situ hybridization. As shown in Fig. 5B, flounder STAT1 was expressed in all tested tissues. However, there was a difference in expression level; expression was low in the liver, skin, and muscle, whereas it was high in the gill, spleen and kidney. This was further confirmed by in situ hybridization, which showed high expression of STAT1 mRNA in the gill, spleen and kidney (Fig. 6). The tissues probed with $\mathrm{SH} 2$ domain probe showed blue appearance and there was no "hot spot" of STAT1 expression in these tissues, and STAT1 expression was detected in most cells in these tissues.

STAT1 is involved in signaling pathways initiated by both IFN- $\alpha / \beta$ and IFN- $\gamma$, which are important to innate antiviral responses and adaptive cell-mediated immune responses, respectively. In both, STAT1 is in an inactivated latent form in the cytoplasm and is activated by binding of IFNs to their receptors. Therefore, basal expression of STAT1 is necessary for a prompt response to a signal. For example, higher basal expression of STAT1 and STAT2 in
A.

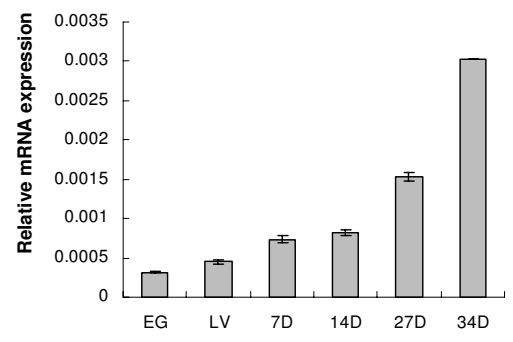

B.

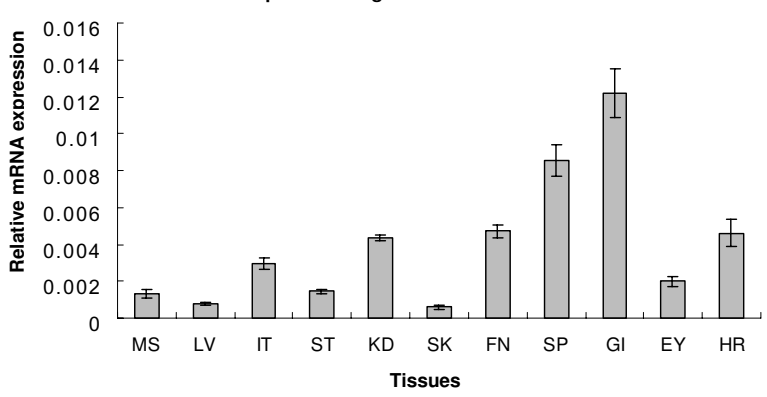

Figure 5

Quantitative real-time PCR analysis of the STATI gene expression (A) Expression analysis of STAT I mRNA at different developmental stages. EG, egg; LV, larva; 7D, 7 day post-hatch; I4D, I4 day post-hatch; 27D, 27 day post-hatch; 34D, 34 day post-hatch. (B) Expression of STATI mRNA in various tissues of the flounder. MS, muscle; LV, liver; IT, intestine; ST, stomach; KD, head kidney; SK, skin; FN, fin; SP, spleen; GI, gill; EY, eye; HR, heart. Data are averages from three replications with standard deviations.

cardiac myocytes results in higher antiviral protection [31]. The gill is the front line of defense when fish encounter foreign substances, including pathogenic microorganisms. Therefore, high expression of STAT1 is necessary for prompt and efficient innate immune responses. Similarly, spleen and kidney play important roles in the adaptive immune response of fish [32], and high expression of STAT1 can be expected. Our results indicate that flounder STAT1 is expressed throughout development and that tissue with high STAT1 expression are involved in defense against pathogens.

\section{Conclusion}

Flounder is one of the main edible fishes in Asia and is also one of the most lucrative fishes in marine culture. However, many problems hamper the mass production of flounder through high-density culture. In particular, frequent mass mortality induced by viral and bacterial infections causes serious damage to the flounder industry. Therefore, biological research on the immune system of flounder is highly important, not only for academic purposes but also for commercial and industrial purposes. We cloned flounder STAT1 and found that the SH2 


\section{Gill}

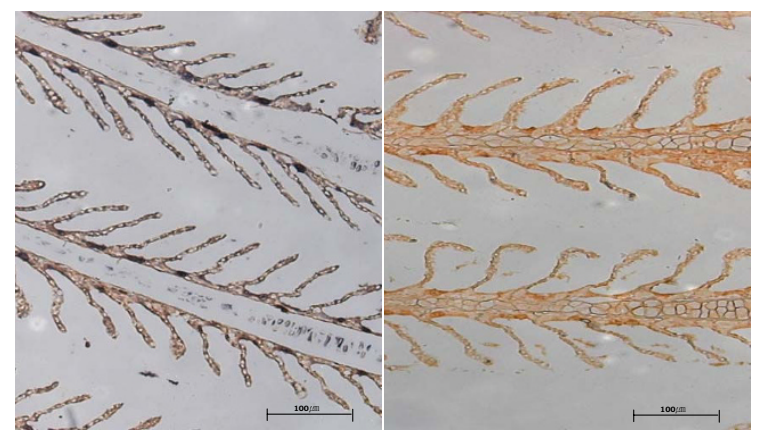

\section{Head Kidney}

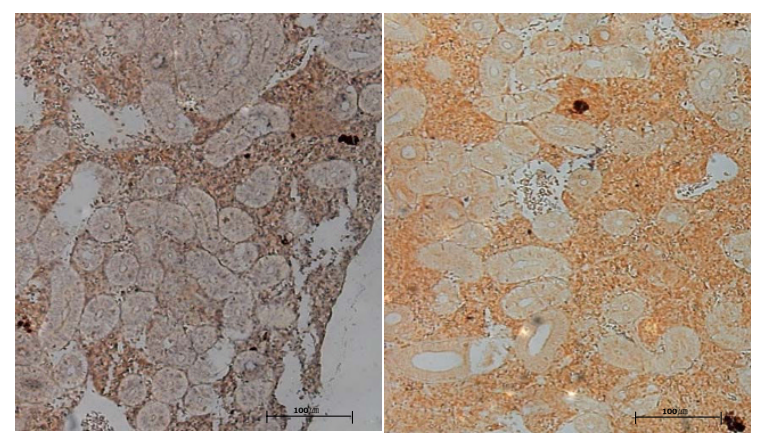

\section{Spleen}

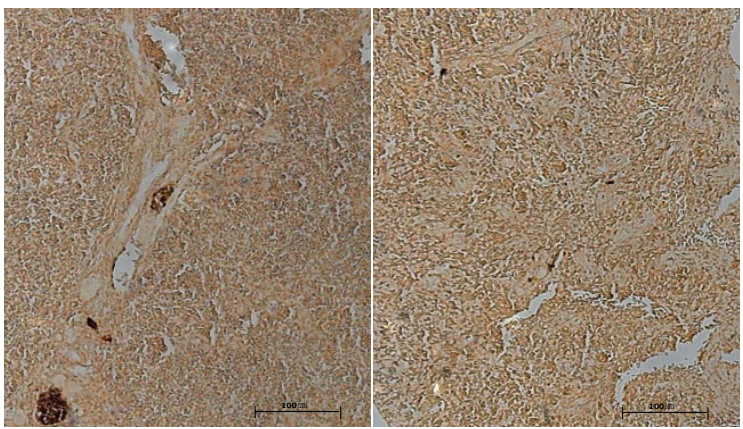

\section{Intestine}

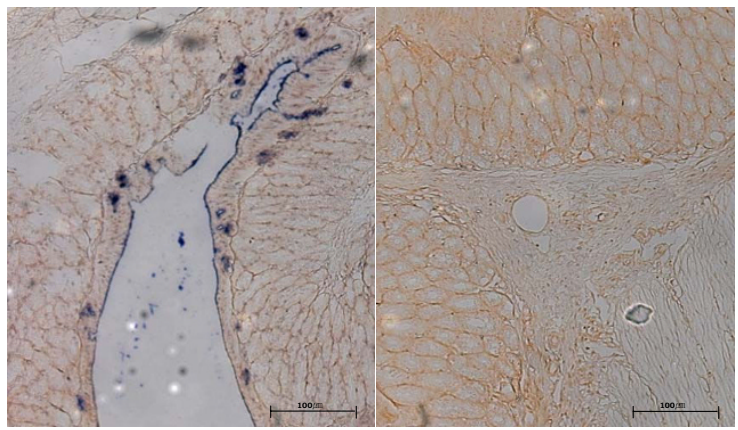

\section{Figure 6}

In situ hybridization of flounder tissues to detect STATI mRNA. Flounder tissues fixed in neutral buffered formalin were probed with a $\mathrm{SH} 2$ domain-specific cRNA probe. The left panels in each tissue hybridized with the probe show blue color, which indicates the presence of the mRNA. Right panels in each tissue showing no blue region are the same tissue probed with a sense probe as a negative control.

domain is conserved. Our results suggest that flounder may use the highly specialized JAK-STAT pathway for cytokine signaling. Further identification of IFN and isoforms of STAT proteins will provide more detail about the signaling and immune responses of this economically important fish.

\section{Methods}

Cloning of STATI CDNA in flounder

A cDNA fragment encoding the partial sequence of STAT1 was obtained by PCR from the brain tissues of olive flounder, Paralichthys olivaceus. A forward degenerate oligonucleotide (STAT5'-1) 5'-TT(T/C)GTIGTIGA(A/G)(A/ C)GICA(A/G)CC-3' and a reverse degenerate primer (STAT3') 5'-GA(A/G)AAIC(T/G)IA(A/G)IA(A/G)(A/G)AA IGT-3' were used for first-round PCR. These primers represent two short amino acid sequences (FVVERQP and SFRLLFT) that are highly conserved in the SH2 domains of zebrafish and mammalian STAT1 (Fig. 1). Total RNA was extracted from $100 \mathrm{mg}$ of flounder brain tissue. Using this RNA as a template, cDNA was synthesized using Moloney murine leukemia virus (MMLV)-reverse transcriptase and subsequently used as the template for the first-round PCR. The PCR product was subsequently amplified by nested degenerative PCR. For this second-round PCR, 5'-TCICTICCIGTIGTIGTIAT-3' (STAT5'-2) was used as a 5' degenerate primer in combination with the STAT3' primer. The successfully amplified cDNA fragment was cloned into a pGEM-T Easy vector (Promega) and sequenced.

The full-length of flounder STAT1 was obtained using rapid amplification of cDNA ends (RACE) with a SMART RACE cDNA Amplification Kit (Clontech) following the manufacturer's instructions. Total RNA $(1 \mu \mathrm{g})$ obtained from liver was used for cDNA synthesis. The gene-specific STAT1 primers STAT1-5RACE (5'-GCAGCTGACAGACGTTAGAGATCAC-3') and STAT1-3RACE (5'-CTGAGTGACAAGTGTCCCGGCAC-3') were used in the RACE of the $5^{\prime}$ and 3 ' ends, respectively. The $5^{\prime}$ and 3 ' cDNA fragments obtained from RACE were cloned and sequenced as described above. 


\section{Northern Blot Analysis}

Total RNA was isolated from flounder brain and zebrafish using TRIzol reagent (Invitrogen) according to the manufacturer's instructions. The RNA samples were resolved in $1 \%$ agarose/formaldehyde gels, blotted onto Hybond-N membranes (Amersham), and hybridized in ExpressHybTM hybridization solution (Clontech). The membranes were probed with ${ }^{32}$ P-labeled zebrafish STAT3 cDNA or the flounder STAT1 cDNA fragment. Hybridized probes were washed in $0.1 \%$ SDS/0.1 SSC at $65^{\circ} \mathrm{C}$ and visualized by autoradiography.

\section{Structural Analysis of Flounder STATI}

The flounder STAT1 SH2 domain was identified using the TBLASTN algorithm on the BLAST server at the NCBI databank. Multiple sequence alignments were done with the CLUSTAL W algorithm in the BCM Search Launcher, and further adjusted by GeneDoc. A phylogenetic tree of the aligned sequences was constructed using the neighborjoining algorithm within MEGA (version 3.0). The accession numbers of the sequences used in the alignments and phylogenetic tree were: olive flounder STAT1 (EF491182), snakehead STAT1 (EF079868), green puffer STAT1 and STAT3 (F307105, AF307106), rainbow trout STAT1 and STAT3 (U60331, U60333), zebrafish STAT1 and STAT3 (NM 131480, BC068320), Japanese medaka STAT3 (AY639947), African clawed frog STAT1 and STAT3 (AY101602, AB017701), chicken STAT1 (NM_001012914), pig STAT1 (NM_213769), Norway rat STAT1 and STAT3 (AF205604, NM 012747), crucian carp (AY242386), and various human STATs (ㄷ471058, NM 139266, NM 005419, NM 139276, NM 003151, NM 003152, NM 012448).

\section{Expression Studies using quantitative real-time $R T-P C R$}

Total RNA was extracted from healthy adult $P$. olivaceus (0.5 kg in body weight), muscle, liver, intestine, stomach, kidney, skin, fin, spleen, gill, eye, and heart, or from flounder at different developmental stages using Trizol (Invitrogen). First-strand cDNA synthesis was performed using the Advantage RT-for-PCR Kit (BD Biosciences). The level of STAT1 expression was detected by RT-PCR using specific primers (STAT1-RT-F: 5'-GATCTCTAACGTCTGTCAGCTG-3' and STAT1-RT-R: 5'-GAGGTCCAGGAT TCCTTCGATC-3'). As a positive control, GAPDH was amplified using the appropriate sense (GAPDH-RT-F: 5'TCCCATGTTCGTCATGGGCGTGA-3') and antisense (GAPDH-RT-R: 5'-ATTGAGCTCAGGGATGACCTTG-3') primers.

Reaction conditions were $94^{\circ} \mathrm{C} / 4 \mathrm{~min} ; 35$ cycles of $94^{\circ} \mathrm{C} /$ $30 \mathrm{~s}, 55^{\circ} \mathrm{C} / 30 \mathrm{~s}, 72^{\circ} \mathrm{C} / 30 \mathrm{~s}$; and $72^{\circ} \mathrm{C} / 10 \mathrm{~min}$. $\mathrm{SYBR}^{\circledR}$ Green (Molecular Probe Inc., Invitrogen) was used to detect specific PCR products. Amplification and detection of SYBR $^{\circledR}$ Green were performed with a MyiQ cycler (Bio-
Rad). The flounder GAPDH gene was used as a housekeeping reference gene to normalize expression levels between the samples. All the data of triplicate experiments were expressed as relative to GAPDH, which was used to normalize for any difference in reverse transcriptase efficiency. Fold change in the relative gene expression to control was determined by the standard $2^{-\Delta \Delta \mathrm{Ct}}$ method of Giulietti et al. [33].

\section{Localization of STATI mRNA by In Situ Hybridization (ISH)}

The flounder STAT1 amplified with specific primers, STAT1-RT-F and STAT1-RT-R, was used to synthesize digoxigenin (DIG)-labeled cRNA probes. The DIG-labeled cRNA probes were synthesized using a DIG RNA labeling kit (Roche). The kidney, spleen, intestine, and gill of a healthy olive flounder were fixed in neutral buffered formalin, dehydrated, impregnated, and embedded in paraffin. After deparaffination and rehydration, 4- to 5- $\mu \mathrm{m}$ thick sections were washed for $5 \mathrm{~min}$ in $100 \%$ ethanol at room temperature and pretreated with Proteinase K (10 $\mu \mathrm{g} / \mathrm{ml}$ ) for $30 \mathrm{~min}$ at $37^{\circ} \mathrm{C}$. Prehybridization and hybridization were performed in DIG Easy Hyb (Roche) solution. A hybridization mix was prepared by adding one volume of hybridization buffer to one volume of antisense and sense probe, giving a final concentration of at least $50 \mathrm{ng} / \mu \mathrm{l}$ of probe. The slides were washed with DIG wash and block buffer (Roche), and the signal was detected using the DIG Luminescent Detection Kit (Roche) according to the manufacturer's instructions. The sections were counterstained with Bismarck Brown Y before observation.

\section{Authors' contributions}

E-MP, JSS and J-HK carried out 5' and $3^{\prime}$ RACE, in situ hybridization, sequence alignment, real time PCR and drafted the manuscript. GK participated in 3' RACE and sequence analysis. JC carried out the cloning of the SH2 domain and southern blot analysis. T-JC participated in its design and coordination and helped to draft the manuscript. All authors read and approved the final manuscript.

\section{Acknowledgements}

This work is funded by a grant from the National Fisheries Research and Development Institute (No. RP-2008-BT-009).

\section{References}

I. Robertsen B: The interferon system of teleost fish. Fish Shellfish Immunol 2006, 20:I72-91.

2. Wesoly J, Szweykowska-Kulinska Z, Bluyssen HA: STAT activation and differential complex formation dictate selectivity of interferon responses. Acta Biochim Pol 2007, 54:27-38.

3. Darnell JE Jr: STATs and gene regulation. Science 1997, 277:1630-35.

4. Levy DE, Darnell JE Jr: Stats: transcriptional control and biological impact. Nat Rev Mol Cell Biol 2002, 3:65I-62. 
5. Bromberg J, Darnell JE Jr: The role of STATs in transcriptional control and their impact on cellular function. Oncogene 2000 , 19:2468-73.

6. Schindler C, Darnell JE Jr: Transcriptional responses to polypeptide ligands; the JAK-STAT pathway. Annu Rev Biochem 1995, 64:62|-5I.

7. Hebenstreit D, Horejs-Hoeck J, Duschl A: JAK/STAT-dependent gene regulation by cytokines. Drug News Perspect 2005, I 8:243-49.

8. Murray PJ: The JAK-STAT signaling pathway: input and output integration. J Immunol 2007, 178:2623-29.

9. Yeh TC, Pellegrini S: The Janus kinase family of protein tyrosine kinases and their role in signaling. Cell Mol Life Sci 1999, 55:1523-34.

10. Platanias LC: Mechanisms of type-I- and type-II-interferonmediated signaling. Nat Rev Immunol 2005, 5:375-386.

II. Herrington J, Smit LS, Schwartz J, Carter-Su C: The role of STAT proteins in growth hormone signaling. Oncogene 2000, 19:2585-97.

12. Yu CL, Meyer DJ, Campbell GS, Larner AC, Carter-Su C, Schwartz Jove R: Enhanced DNA-binding activity of a Stat3-related protein in cells transformed by the Src oncoprotein. Science 1995, 269:81-3.

13. Samuel CE: Antiviral actions of interferons. Clin Microbiol Rev 200I, 14:778-809.

14. Durbin JE, Hackenmiller R, Simon MC, Levy DE: Targeted disruption of the mouse STATI gene results in compromised innate immunity to viral disease. Cell 1996, 84:443-50.

15. Meraz MA, White JM, Sheehan KC, Bach EA, Rodig SJ, Dighe AS, Kaplan DH, Riley JK, Greenlund AC, Campbell D, Carver-Moore K, DuBois RN, Clark R, Aguet M, Schreiber RD: Targeted disruption of the STATI gene in mice reveals unexpected physiologic specificity in the JAK-STAT signaling pathway. Cell 1996, 84:43I-42.

16. Kim HS, Lee MS: STATI as a key modulator of cell death. Cell Signal 2007, 19:454-65.

17. Oates AC, Wollberg P, Pratt SJ, Paw BH, Johnson SL, Ho RK, Postlethwait JH, Zon LI, Wilks AF: Zebrafish stat3 is expressed in restricted tissues during embryogenesis and statl rescues cytokine signaling in a STATI-deficient human cell line. Dev Dyn 1999, 215:352-70.

18. Aoki T, Hirono I, Kim MG, Katagiri T, Tokuda $Y$, Toyohara $H$ Yamamoto E: Identification of viral induced genes in Ig+ leucocytes of Japanese flounder Paralichthys olivaceus, by differential hybridization with subtracted and un-subtracted cDNA probes. Fish Shellfish Immunol 2000, 10:623-30.

19. Lee EY, Park HH, Kim YT, Choi TJ: Cloning and sequence analysis of the interleukin-8 gene from flounder (Paralychthys olivaceus). Gene 200I, 274:237-43.

20. Tamai T, Shirahata S, Noguchi T, Sato N, Kimura S, Murakami H: Cloning and expression of flatfish (Paralichthys olivaceus) interferon cDNA. Biochem Biophys Acta 1993, I I 74:182-6.

21. Secombes C, Zou J, Daniels G, Cunningham C, Koussounadis A Kemp G: Rainbow trout cytokine and cytokine receptor genes. Immunol Rev 1998, 166:333-40.

22. Horvath CM: STAT proteins and transcriptional responses to extracellular signals. Trends Biochem Sci 2000, 25:496-502.

23. Horvath CM, Wen Z, Darnell JE Jr: A STAT protein domain that determines DNA sequence recognition suggests a nove DNA-binding domain. Genes Dev 1995, 9:984-94

24. Wen Z, Zhong Z, Darnell JE Jr: Maximal activation of transcription by Statl and Stat 3 requires both tyrosine and serine phosphorylation. Cell I995, 82:24I-50.

25. Improta T, Schindler C, Horvath CM, Kerr IM, Stark GR, Darnell JE Jr: Transcription factor ISGF-3 formation requires phosphorylated Stat9I protein, but Statl 13 protein is phosphorylated independently of Stat9 I protein. Proc Natl Acad Sci USA 1994, 9 I:4776-80.

26. Lewis RS, Ward AC: Conservation, duplication and divergence of the zebrafish stat5 genes. Gene 2004, 338:65-74.

27. Zhang Y, Gui J: Molecular characterization and IFN signal pathway analysis of Carassius auratus CaSTATI identified from the cultured cells in response to virus infection. Dev Comp Immunol 2004, 28:2 I I-27.

28. Sung SC, Fan TJ, Chou CM, Leu JH, Hsu YL, Chen ST, Hsieh YC, Huang CJ: Genomic structure, expression and characteriza- tion of a STAT5 homologue from pufferfish (Tetraodon fluviatilis). Eur J Biochem 2003, 270:239-52.

29. Takeda K, Noguchi K, Shi W, Tanaka T, Matsumoto M, Yoshida N, Kishimoto T, Akira S: Targeted disruption of the mouse Stat3 gene leads to early embryonic lethality. Proc Natl Acad Sci USA 1997, 94:380I-4.

30. Duncan SA, Zhong Z, Wen Z, Darnell JE Jr: STAT signaling is active during early mammalian development. Dev Dyn 1997 , 208:190-8.

31. Zurney J, Howard KE, Sherry B: Basal expression levels of IFNAR and Jak-STAT components are determinants of cell-typespecific differences in cardiac antiviral responses. J Virol 2007 8I I: I3668-80.

32. Kaattari SL, Irwin MJ: Salmonid spleen and anterior kidney harbor populations of lymphocytes with different B cell repertoires. Dev Comp Immunol 1985, 9:433-44.

33. Giulietti A, Overbergh L, Valckx D, Decallonne B, Bouillon R, Mathieu C: An overview of real-time quantitative PCR: applications to quantify cytokine gene expression. Methods 200I, 25:386-40।
Publish with Bio Med Central and every scientist can read your work free of charge

"BioMed Central will be the most significant development for disseminating the results of biomedical research in our lifetime. "

Sir Paul Nurse, Cancer Research UK

Your research papers will be:

- available free of charge to the entire biomedical community

- peer reviewed and published immediately upon acceptance

- cited in PubMed and archived on PubMed Central

- yours - you keep the copyright
BiolMedcentral 